\title{
IN THE CONTEXTS OF THE POSSIBLE: LIBRARIES AND MUSEUMS AS INCENDIARY CULTURAL INSTITUTIONS
}

Great CUltural institutions-incendiary cultural institutions-feed flames that illuminate the human capacity to imagine the possible. When we consider our institutions as dramatic stages or provocative forums-places where human beings present themselves to each other, act to change their cognitive lives, perform the passions of their searches, frame their hopeful inquiries, tentatively assert their aspirations-we begin to understand that we preside over a place where something essential and revolutionary goes on. But what situations for learning could live up to the metaphor of flame and fire? What would such an institution be? How might an incendiary cultural institution think of itself?

Whenever we speak about libraries and museums, and whenever we consider the power of institutions to address and respect the integrity of human intellect and human becoming, the incendiary minds and watchful eyes of Thomas Jefferson and James Madison are in the room. So are the minds and eyes of our communities and cultures, those who live and grow strong in our civil societies, our families and schools, all contemplating the challenges of their lives and hoping to be addressed and assisted in the course of their own individual human becoming.

When people come together as learners, they have an opportunity to understand that cultural institutions-libraries, museums, historical societies, botanical gardens, archives, zoos, parks - are grounded in the idea 
that a culture requires places, forums, working laboratories for cognitive change, where voices can be heard expressing hopes and aspirations in the contexts of the possible. When we capture and express such possibilities, we come to own a view of the future. In such places, the truly open sources of our society, there is also equality in those possibilities of ownership, ensuring that knowledge is not privileged to any but those who can learn from the records and objects at hand and from other people in mutual engagement with a common world.

In this coming together we find several challenges: overcoming the isolations of experience, our separations and insularities, the anxieties and distances among us; creating the language of observation, exploration and common exchange; building accord on what we want to have happen, deciding what we want our institutions to do and be; and finding the courage to consider the mutual unknown. This is exactly why cultural institutions exist: to manage our cognitive challenges by creating good processes and educative structures, to recognize and celebrate good questions when they appear, and to engage with the personal narratives of human beings as they learn.

And yet, the "personal" has become increasingly elusive, as our connections and transactions become both increasingly virtual and increasingly transient. As we negotiate our way to the learning structures we need, we may feel that something of our own is missing or possibly lost in the tensions that define our lives - tensions between our families and our work, feeling safe and feeling fearful, continuity and change. These are all tensions of knowledge, discrepancies between what we know and what we do not yet know, the hopes of having enough information to manage a complex life with extraordinary unknowns in it.

To these tensions, we might add the observation that the values that define our lives, inform our educational systems, and are transmitted to our children may not be coming from us but, instead, from somewhere outside us. Where, then, do they begin, and how do they reach us and shape our 
environments? These are times when the unresolvable tacit questions we are asked to live with may be: What does it mean to be a human being? What are the values of a person and of personal acts? What does it mean to be a human being among other human beings?

We who are advocates for cultural institutions as sources of structure, continuity, and transformation may be sensitive to less identifiable, even subtler, erosions in public altruism. In our own lives we may notice fewer opportunities for reflection and self-renewal, more difficult connections to others, an inability to find a common voice. In our work we may experience less cooperation and outreach, less mutual respect, less self-respect. These erosions are especially important, of course, because they affect the grounding impulses for teaching, learning, self-exploration, and confident engagement with one's life. To lose them, even a bit of them, is disheartening; and so we must seize what we have.

In "Utterance," by the poet W.S. Merwin, "Sitting over words / very late," hears

a kind of whispered sighing

not far

like a night wind in pines or like the sea in the dark

the echo of everything that has ever

been spoken ...

Against the "the echo of everything that has ever been spoken," the tensions and senses of loss, we take the life we have, create communities of all kinds, and build harbors in them: the institutions and collective settings where commonalities and stories and the mutual transmissions of cultural gifts are exchanged. These are the institutions and settings doing the formative cultural mediation that is the practical work of civil society, the

1. W.S. Merwin, "Utterance," in A Book of Luminous Things, ed. Czeslaw Milosz (New York: Harcourt Brace, 1996). 
ways a community has of causing or encouraging favorable things to happen. $^{23}$

In the case of libraries and museums, the favorable thing we want to have happen is the development of learners, alone and in groups and families, whose lives are engaged with each other, embracing each other over their mutual reflections. For us, it is also the confirmation of observers, readers, and thinkers, nourishing and encouraging them to experience and synthesize new information. That critical work is the setting of minds on fire in such a way that they inch their edges forward toward new knowledge and each other. Jean Bethke Elshtain writes, "Civil society isn't so much about problem solving as about citizen and neighbor creating." And I will add learner creating, memory creating, and future creating. As Senators Dan Coates and Rick Santorum write, "When civil society is strong, it infuses a community with its warmth, trains its people to be good citizens, and transmits values between generations." 5 To me, this is what our cultural institutions must be about, what we who work in them must be for.

Certainly, it is what we at our best do better than anyone else. We find the energy of people who arrive in the library, the garden, the museum, or the

2. E.J. Dionne Jr., "Introduction," in Community Works: The Revival of Civil Society in America, ed. E.J. Dionne Jr. (Washington, D.C.: Brookings Institution Pr., 1998), 3.

3. Former Senator Bill Bradley defines civil society in this way: "Civil society is the place where Americans make their home, sustain their marriages, raise their families, hang out with their friends, meet their neighbors, educate their children, worship their god. It is in the churches, schools, fraternities, community centers, labor unions, synagogues, sports leagues, PTAs, libraries and barbershops. It is where opinions are expressed and refined, where views are exchanged and agreements made, where a sense of common purpose and consensus are forged. It lies apart from the realms of the market and the government, and possesses a different ethic. The market is governed by the logic of economic self-interest, while government is the domain of laws with all their coercive authority. Civil society, on the other hand, is the sphere of our most basic humanity - the personal, everyday realm that is governed by values such as responsibility, trust, fraternity, solidarity, and love. In a democratic civil society such as ours, we also put a special premium on social equality-the conviction that men and women should be measured by the quality of their character and not the color of their skin, the shape of their eyes, the size of their bank account, the religion of their family, or the happenstance of their gender." ("America's Challenge: Revitalizing Our National Community," in Community Works, ed. E.J. Dionne Jr. [Washington, D.C.: Brookings Institution Pr., 1998], 108-9.)

4. Jean Bethke Elshtain, "Not a Cure-All: Civil Society Creates Citizens, It Does Not Solve Problems," in Community Works, ed. E.J. Dionne Jr. (Washington, D.C.: Brookings Institution Pr., 1998), 27.

5. Dan Coats and Rick Santorum, "Civil Society and the Humble Role of Government," in Community Works, ed. E.J. Dionne Jr. (Washington, D.C.: Brookings Institution Pr., 1998), 102. 
zoo to renew and reinvent themselves and so to renew and reinvent their awareness of the culture they inhabit and own. Our cultural institutions recognize that every mindful person is a community's treasure. To serve in such institutions is to exist in an alliance of trust and common weal with a community. The preposition is important: it is the institution that is not just for, but with, its community in trust that thrives most fully. ${ }^{6}$

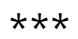

How are cultural institutions part of common human motives, beyond the fundamental idea of keeping things and preserving them against the threat of loss and forgetfulness? Having a museum and a library in a community is always about the community having an informed present and future. These institutions are devoted to the unknown and to the evidences of possible knowledge constructed on the foundations of the known.

Museums and libraries share common themes.

- They share a horizon, attending to the cognitive, educative, and developmental possibilities of people over the life span, apart from the interests and expectations of schools. They do not give credits or certificates. They do not graduate anyone. There are no bells, no recess. But museums and libraries are for learning as it perhaps ought to happen best, in what we might call an open configuration of structures and structures-withinstructures evoking the natural continuities of cognitive experience.

- They have similar logic and patterns of organization. Although we may be challenged as independent observers, we can expect to find our ways in museums and libraries by paying reasonable attention and with minimal intervention and instruction. In my experience, every public cultural 
setting is constructed for direct, independent entry by users who typically are given articulate, logical, public organization systems and coherent narratives for passage or process. Each institution employs professionals and others whose specific task is to consult, direct, facilitate learning, and assist the user in designing an individual experience of the collection. Apart from the more or less logical systems created for access (such as catalogs and maps), the physical structures of museum and library buildings generally reflect a logical likeness or design and a continuity of discipline, topic, or material. Museums and libraries are designed structures with a logic that is, at its best, visible and coherent. They are settings that evoke a path that we can experience as our own path.

- In what they offer and how they offer it, museums and libraries are laboratory-like environments. In content and power, they are potentially volatile and surprising, and they require acute attention to detail. Borrowing from John Dewey, one might say that museums and libraries are places for events that have not happened yet. By their nature, our cultural institutions are designed for cognitive experiments, for proximities and juxtapositions of images and ideas that cannot occur in any other institutions. And in libraries or museums, every user's step is a form of question, from generic to specific. Because library and museum use is active and experimental, not passive, we might further say that such experiences are empirical, revealing logical connections and decisions that require direct cognitive impressions of artifacts and tools. Holding these artifacts and tools for us, they are places where our handmade lives, our crafted truths, are shaped.

- Both institutions, even those with limited collections and services, are engaged in organizing provocative and complex realms of knowledge that exist in parallel to corresponding experiential worlds outside. Both institutions must forge illuminating links to the world beyond their walls. They are culturally charged in the connections they make to situations and 
settings beyond the institutions themselves. In fact, they depend on the world outside, each a treasury that is renewed by the progress of its exterior cultures. As institutions, they are complex in their potential interactions with their communities and each other. It also is clear that libraries and museums never become simpler; their content never becomes less complex.

- In a museum or library, nothing moves forward without a question, pursuit, or objective, a mix of risk and hope. Even casual use of a cultural institution typically takes on an aim or plan within the limits of time, interest, or skill. It follows from the need to find something, even if invisible or inexplicable. Purposeful use in both institutions might be described in searching language: "I am looking for," "I want to see," "I am trying to find," and so on. Museums and libraries need to cultivate and follow the multiple forms of a searching sensibility.

- Museums and libraries integrate past and present, embodied in the user. A thoughtful person in the museum or library brings a history of knowing, reflecting, and understanding to bear upon the moment of use and the design of the search at hand. In the learner's intellectual processes, everything discovered is compared to past experiences and previous knowledge. (Of course, he or she also carries a history of confusion, questioning, and mystery.) Not only does the user encounter the new and the historic, he or she also encounters the past that is carried within, as well as an emerging new idea. The here and now blends its dimensions with the once and past. No other institutions require their users to travel in so many private dimensions of time and space at once.

- Wherever inquiry takes place, literacy guides the discoveries of the user. Language helps the user to find information and to understand and process it. The critical intellectual factors of explanation, articulation, and synthesis are experiences of language. Without words and a level of fluency, we cannot articulate in public or private what has happened in 
the present of a work, an idea, an object, or a text. Words enable us to capture and then hold and contain what we witness.

- Museums and libraries let us work and think for as long as we live. Among institutions of learning, only libraries and museums allow multiple generations to reflect side by side. This means that the interests of an individual across the life span can be explored and renewed over time, transmitted to others, and will never be exhausted from youth to old age. It also means that young and old can gather to tell the stories stimulated by words and things. In museums and libraries, age, knowledge, family, and educational or economic status are not barriers to use. Perhaps it is time to suggest that formative cultural institutions construct the lifelong learner far more directly than any classroom does.

- Inside cultural institutions, we are free within limits to do as we care to do and free with no limits to think as we care to think. Unlike the school, where the learner typically must submit to the values and interpretations of an instructor, in the cultural institution the user is largely in control of the situation for experience. Moreover, the institution succeeds only when it has responded to the needs of the individual user. The responsive institution makes direct, authentic, and unrestricted experiences possible for the user and then helps the user to illuminate those experiences and see them in further, deeper, richer, more extensive contexts.

- Museums and libraries succeed through the useful tensions combining intellectual work and intellectual play, the known and the unknown, the conventional and (sometimes right next to it) the revolutionary. When we enter a cultural institution, we find an environment that challenges and tempts us, even as we find more to know than we can possibly master. For the mindful learner, a single possibility can create a powerful tension between the desirable and the actual, the clear and the shrouded. These are the tensions of learning. 
- The structure and process of the museum and the library are the same for every learner: One must begin where one is, assessing the parts of knowledge to be grasped and mastered over time. The learning is connective and integrative, evolving slowly and not arriving as if for an examination. Here, learners fabricate and build their own minds; they do not wait to receive the mind of a professor or other teacher. Here, learners combine pieces for themselves. Nothing about this is easy.

- Ultimately, both museums and libraries are institutions that give information to their users - through vision, words, comparisons, suggestions, or the powerful presence of a reorganizing concept, an insightful connection. Libraries connect information to the processes of individual cognitive, personal, imaginative, economic energy. Museums connect information to the experiences of awe and surprise that follow from seeing the thing itself that has been brought before us.

Increasingly, we are challenged to understand how these common themes take different forms in museums and libraries, how they might be woven together more explicitly in the cultural institution, and how our historic community genius can invigorate the patterns of thought and aspiration that unify their missions. We are challenged to understand what these two institutions might become, together. We are challenged to encounter the idea that cultural institutions have a common agenda and that libraries and museums both hold and construct a powerful vision of inquiry and knowledge in culture.

$* * *$

If we agree on some of these common qualities among cultural institutions, we also might consider several fundamental ideas that seem to sustain such institutions in our lives. Why do human beings need these institutions, these collections, this information? What unknowns, wants, and urgencies 
do these institutions mirror in our hearts and minds? This is an individual perspective on reasons for having museums and libraries; reasons for rescuing, conserving, and sustaining the treasures of culture and identity; and reasons for sharing their conjoint value and power with fellow citizens.

Human beings collect, organize, and keep evidence of their lives and cultures for multiple reasons: the pleasures of ownership; personal identification; the cultivation of knowledge and the advancement of scholarship; the possibility of change through reflection. We are certain, because we see the events of our own lives and the lives of our ancestors as worthy, that we are obligated to contain and illuminate the artifacts and ideas of persons now gone. Objects of art, memory, identity, or wisdom bear in common the touch of human, caring hands. Their presence in a contemporary world suggests that among their qualities, simple endurance may be worth our attention and reflection. And so we keep these institutions in order to understand and ensure the enduring qualities of a handmade life.

Reasons for keeping and understanding objects and texts and for explaining their lasting strength are more than private. They are sources of insight and recognition for the individual and for other learners in groups. But if we assume that such insight and thought go with the user, beyond the institution, we also must assume that cultural treasures are alike in that they are about the future more than they are about the past. If our record is to be of use, it must be given to the future. The formal institutions we have built to hold evidence of our civilization are too often regarded as precious reliquaries or display cases. Instead, they should be seen as formative and interactive, creating whatever is to happen next in the cognitive life of the user. Having a museum or library in a community is about the community having both a present and a future because these institutions are devoted to exploring the evidence of the possibilities at hand.

Across time and geography, our public cultural institutions are grounded in concepts and intentions that we rarely articulate. What are the deepest 
cultural purposes of cultural institutions? Why do we strive to contain, keep, and narrate the documents and artifacts of human knowledge and activity? What do we construct when we construct a cultural institution? What do we assemble for ourselves when we build a library or a museum?

- We build collections because we strive to keep and preserve evidence of human continuity and to sustain remembrance. We strive not to forget how we have become who and what we are in order to be mindful of where we began. Cultural institutions hold artifacts and their legacies when our memories as humans cannot. This makes possible the transmission of meanings among distant generations.

- We construct and systematize collections because we strive to contain and organize authoritative materials for reference and verification. By looking at the original artifact - the edited manuscript, the sculpted bone, the tortured score-we are nearly able to look at (and into) the moment of its inspiration. By retaining the records of masterful ideas and objects, we keep the possibility of drawing new insights from them. Museums and libraries allow us the opportunity, generation after generation, to respond separately to the questions, "Is it true? And what, exactly, is its truth?"

- As inquirers, we strive to discover and study materials for new knowledge and new syntheses of evidence. Driven by questions, we use our cultural institutions as places where we can first follow threads and then weave garments. If every school were to close tomorrow, intellectual growth might continue in cultural institutions, where we would likely find and teach each other. These settings are always poised to rescue human cognitive processes when schools fail to sustain and nurture them and even when the Internet undoes the tendency to have an original, private, unshared thought.

- In museums and libraries, we strive to delight and inform ourselves with 
observations and reflections on human accomplishment. Human beings have always reserved their greatest delights for moments of learning. Parent and child are bonded as much by the learning transmitted between them as they are by blood. What we find delightful, we wish to have held forever before us, Faust-like. The museum or library does this, while generously allowing us to retain our souls.

- We strive to integrate and verify our experiences in the larger culture. Our cultural institutions are mirrors for the people and societies that construct them, naturally. But in each personal discovery or observation a learner also finds a mirror of lived experience: "I remember an object like this in San Francisco." "The quality of light in this work appears sometimes in Copenhagen." "The evolution of tools fascinates me and leads me on." "My grandparents were once in this part of the world." We enter and leave with what we know, but our knowing is different when we depart the institution because we have clarified, augmented, or revised what knowledge we had. Or what we know is in the process of becoming different knowledge because we are present, working to understand things. Because what we know configures who we are, we also might say that the crafting of truth in cultural institutions is a process of becoming, renewing, or confirming ourselves.

- We strive to settle fears of loss. We seem at times to be particularly haunted by loss and the fear of loss. Change, the arrival of strangers, the frequency of feeling discontinuous with the past, the terror of beginning again all advance the sense of eroding integrity in our lives. As the greatest of cultural educators, the cultural institution can make explicit links between the past and future, drawing us toward an understanding of great, immutable themes. In doing so, it can help us gain cognitive control over an otherwise unimaginable transition and to place ourselves clearly within our own times, integrated and not excluded. A museum or library collection allows us to revisit and reconsider the differences between what 
was and what is and to see ourselves in continuity with those who preceded us and those who will follow us.

If museums and libraries are to recognize their common future and reorganize themselves to address it, generalizations such as those offered in this text will require exploration and reflection based on a strong grounding in empirical observations and educational theory. The individual learner; the family as a learning organism; the process of sense-making in the presence of an unknown; the continuities and connections among learners who speak to each other and make their stories, fears, and learnings known - we need to understand these invisible things even more than we need to understand the histories of texts and objects. Museums and libraries have one research agenda that overshadows all others: we need to know more about how individual learners renew themselves by exploring their literacies and possibilities, and we can learn this best by talking directly to people.

The final concept unifying museum and library is the idea that all cultural institutions must act on the tenet that every mindful person is a community's treasure. As our culture changes, the culture of every institution needs to find new forms of professional thought grounded in a new cognitive environment. The truly educative institution will experiment with new ideas of professional service to the exploring user. In a world that becomes increasingly virtual, cultural institutions must be challenged to redesign themselves to become face-to-face forums where the questions and controversies of a living culture can find their form and be debated. It is through such forums that human beings will experience the realities of democratic cultural literacy and may come to embody the tensions of being both responsible citizens and mindful people. There is no country on earth without the need for such forums.

\section{$* * *$}

How does the incendiary institution think of itself? It must understand its 
own energy and how that energy attracts and engages its users. How does it lead people in, involve them with their own choices and with other human beings, help them to understand the structures at hand, and teach them how to move among those structures with eyes open? The incendiary institution never compromises its respect for the open-eyed user.

Such users will increase in number when the institution addresses them and the problems that learning presents to a contemporary life. As people experience the inexorable growth of both the tasks and the information at hand, there also will be a common increase in ambiguity and irresolution. How do we know what we need next? How do we confirm the accuracy or truth of our observations? What does learning in one frame of our lives (as parent or companion) mean to the learning we carry out in other frames of our lives (as colleague, designer of new experiences, educator of other adults)?

It is a commonplace that receiving and deciding about immense amounts of information increasingly requires our time and attention if we are to be appropriately responsive to our world. And yet, our lives then become less our own because as messages and information increase, the more we must think on the horizons of others, contend with the structures and assumptions of others, and negotiate meaning and think critically in worlds designed or deeply influenced by others.

And so the living challenge to any person is double-edged: to live strongly on one's own horizon and yet also to adapt our horizons among others in order to find contexts of what we want, what we see, and what we hope for. No one can meet the challenges of such a life without being a passionately critical thinker, an author of one's own experience, and a cautious master of one's own intellect. In a culture where "knowledge" arrives unbidden instantly, it is problematic to confirm its authority, value, and relevance; and so we need to question. The design of real, not surrogate, experiences becomes important as we become increasingly remote from living a selfconstructed life; and so we need ways to determine what is authentic. And 
when information is unlimited in both speed and density, it is not good for reflection; and so we need to slow it down and leaven it with our own salient ideas and values.

As I tell my students, our task is to slow down the information revolution. This is also every learner's task.

Reflection is essential for understanding the configuration of the worldthe mass of influences that create human experience-and its concomitant tensions, balances, processes, and assumptions. It will always be essential for any person who strives to move forward toward wholeness against fragmentation, toward integrity against compromise, and toward fearlessness in the presence of things unknown. As ever, learning and reflection will depend on engaging ceaselessly with the processes that configure a cognitive experience: planning, questioning, remembering, pursuing, discovering, evaluating, constructing, and connecting.

When we face our primary task as adults - to arrive at a working sense of identity and integrity - we have no choice other than to do it as learners led by our own thoughts and not solely by the thoughts and horizons of others. In cultural institutions, people must always undertake this courageous task against the odds. The mass, the authority, and sometimes the intractability of our institutions require great strength of mind if we are to overcome both brilliance and awe in order to see the small traces of an inspired hand. But even in our mindfulness (and here is one of the tensions that will not go away), we also must be permeable to the living experiences and words of others. We must feel safe enough in our own lives to encounter new questions that expand our grasp, even though they may at first make us fearful of change.

Learning will take place as it has always taken place in the contexts of the possible: 
1. A human being will create a question in a situation of complexity.

2. His or her question will stimulate a felt need to pursue information in multiple formats, wherever that may lead.

3. The information will create more questions, lead to more or less useful information.

4. The problem, its contexts, what it means to the learner, and an array of possible questions will all become clear.

5. The first step toward changes in thought, attention, or behavior also will become clear.

These are all incendiary moments. They cannot occur without structures and processes or a logical system of informing paths.

These elements must be present in the situation if learning is to take place:

- assistance, freely given by a mentor, a model, a source of information or referral, a person who speaks the language of the learner; and access to this person, meaning opportunities to create questions and develop a relationship;

- tools, a broad array of adaptive and generative, convivial tools (the term is Ivan Illich's); tools that suggest syntheses, ideas for recombination and exploration; tools that lead a learner on, stimulating new responses to experience; tools that assist the user to transfer skills and observations to another place and time;

- autonomy, meaning independence from authority, freedom from any evaluation other than meeting the learner's own satisfaction, freedom to accept or reject a mentor;

- control and authorship of an inquiry, for example, frequent opportunities to revise the themes and patterns of an inquiry or to abandon it altogether;

- a forum or a conversation in an open environment where learners can participate in mutual conversations with other learners.

People come to museums and libraries and look to them as places to hold 
things still, as the world has fewer and fewer places of stillness in it. That is a critical thing to do. And yet, at the same moment that it offers stillness in a turning world, the great cultural institution also must understand itself to be challenging, a creator of learners and thinkers, a setting where mindfulness cannot possibly be abjured. For any learner, of any age, the great library or the great museum must be an advocate for new thinking, based on the astonishing, moving evidence in treasured texts and objects. Only the place that has a heart of fire (and not of ice) is the one where learning can happen best.

Sustenance for the mind of the future will come from excellent information near at hand, as it always has; but it also will come from collaboration among human beings in an alliance for knowledge, identity, and mere connection to another person, as it always has. Every day of service in a cultural institution provides an opportunity to reinvent the idea of a helping mind, reconfigure a repertoire of ideas and tools, and construct connections to whatever might happen next. We may slowly come to understand that every life bears its own unfinished issues and is unfinished in a different way. In a world often characterized by loss and fear, certain acts of human rescue and survival can occur only in the places where a culture continuously transforms itself through human associations, forged in the presence of the unknown. In this way, the constructive cultural institution contributes to the integrity of its culture.

Our questions, like telescopes or microscopes, are instruments that concentrate our attention and allow us to focus on those parts of the unknown that engage us most. Without such mechanisms, we cannot understand the dimensions hidden from our vision. Whenever we come together to engage in such conversations, we have made a place that is, of course, full of questions itself; and these questions do not become fewer as an evening wears on. And so we must arrive at last at what may be the best question of all, here left for others to consider through the arts of practice and the human gifts of reciprocity and mutual engagement: What happens when 
caring minds meet? It is with this question that the incendiary cultural institution must regard itself. 